\title{
LÍNGUAS ADICIONAIS NO ENSINO FUNDAMENTAL: EXPERIÊNCIAS DIDÁTICO-PEDAGÓGICAS E CONSTRUÇÃO DE POLÍTICAS LINGUÍSTICAS INTERCULTURAIS/ TRANSLÍNGUES EM CONTEXTO DE FRONTEIRA
}

Additional Languages in Elementary School: Teaching Experiences and Intercultural/Translingual Language Policies in a Border Context

Laura FORTES Universidade Federal da Integração Latino-Americana laura.fortes@unila.edu.br https://orcid.org/0000-0001-9099-1802

Jorgelina Ivana TALLEI Universidade Federal da Integração Latino-Americana jorgelina.tallei@unila.edu.br https://orcid.org/0000-0001-8486-0881

João Lucas Cavalheiro CAMARGO Universidade Estadual do Oeste do Paraná lucas.camargo_@hotmail.com https://orcid.org/0000-0003-3746-1225

Renata Alves de OLIVEIRA Universidade Estadual do Oeste do Paraná renatamacska@gmail.com https://orcid.org/0000-0003-1913-5469

Marcia Palharini PESSINI Instituto Federal de Educação, Ciência e Tecnologia do Paraná marcia.pessini@ifpr.edu.br https://orcid.org/0000-0002-8609-5842

Lívia Cristina Carvalho da FONSECA Universidade Estadual do Oeste do Paraná lifonseca13@gmail.com https://orcid.org/0000-0002-3425-5007

Isabella Cristina Haruna MURAKAMI Universidade Estadual do Oeste do Paraná isaharunamr@gmail.com

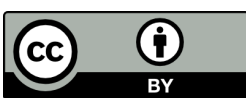


RESUMO: Neste trabalho, relatamos experiências de ensino de línguas adicionais no Ensino Fundamental - Anos Iniciais, por meio da construção de políticas linguísticas e educacionais no âmbito de projetos de pesquisa e de extensão vinculados a um Acordo de Cooperação (Universidade/Prefeitura). Dentre as ações estabelecidas pelo acordo, destacamos a formação continuada para as docentes da rede municipal, que objetivou trabalhar a interculturalidade e o acolhimento em contexto de fronteira. Além do curso de formação, implementou-se outra ação indutora de políticas linguísticas e educacionais: a oferta, de modo experimental, de dois cursos (inglês e espanhol) para estudantes do Ensino Fundamental - Anos Iniciais. Adotou-se um enfoque teórico-metodológico intercultural/discursivo, partindo da concepção de línguas como repertórios linguísticos, envolvendo gêneros, estilos, práticas, discursos e interações nas quais a criança se insere diariamente. Assim, o currículo-base do curso foi planejado considerando os conteúdos interdisciplinares, as línguas/sujeitos em contexto de fronteira e as possibilidades de experiências de interculturalidade e de práticas translíngues. Os relatos de experiência aqui apresentados enfocam reflexões pertinentes ao processo de implementação do curso experimental de língua inglesa, discutindo a elaboração de materiais didáticos, a formação dos/as ensinantes-aprendentes, os recursos didático-pedagógicos e a interculturalidade vivenciada em sala de aula. PALAVRAS-CHAVE: Línguas Adicionais; Políticas Linguísticas; Interculturalidade; Práticas Translíngues.

ABSTRACT: In this paper, we report on experiences of additional language teaching in Elementary School, through the construction of linguistic and educational policies in the scope of research and extension projects linked to a Cooperation Agreement (University/City Hall). Among the actions established by the agreement, we highlight in-service teacher education for municipal schoolteachers, which aimed at discussing interculturality and hospitality in border contexts. In addition to the development course, another action was implemented to promote language and educational policies: English and Spanish classes offered on an experimental basis for Elementary School students. An intercultural/discursive theoretical-methodological approach was adopted, drawing on the conception of languages as linguistic repertoires, involving genres, styles, practices, discourses and interactions the child engages in daily. Thus, the course core curriculum was planned considering the interdisciplinary contents, the languages/ subjects in a border context and the possibilities of intercultural experiences and translingual practices. The experiences reported in this work focus on reflections relevant to the implementation of the experimental English language course, discussing the development of te- 
aching materials, teachers-learners education, didactic-pedagogical resources, as well as interculturality experienced in the classroom. KEYWORDS: Additional Languages; Language Policies; Interculturality; Translingual practices.

\section{INTRODUÇÃO}

Neste trabalho, relatamos experiências de ensino e de aprendizagem de línguas adicionais $^{1}$ no Ensino Fundamental - Anos Iniciais da rede municipal de Foz do Iguaçu, Paraná, no segundo semestre de 2019. As práticas pedagógicas em questão foram vivenciadas no âmbito do Projeto de Pesquisa O currículo como instrumento linguístico: ordem e organização de saberes em contextos educacionais multilíngues e translíngues (FORTES, 2016a), ${ }^{2}$ em articulação com o Projeto Pedagogia Intercultural: ensino de linguas no ensino fundamental ${ }^{3}$, que constituiu uma das ações do Acordo de Cooperação entre a Universidade Federal da Integração Latino-Americana (UNILA) e a Prefeitura de Foz do Iguaçu (por meio da SMED-Secretaria Municipal de Educação) no final do ano de 2018 (UNILA, 2018), contando com a participação de colaboradores(as) de duas outras instituições públicas da cidade: Universidade Estadual do Oeste do Paraná (UNIOESTE) e Instituto Federal do Paraná (IFPR). O Acordo de Cooperação, ainda vigente, tem como objetivos principais:

a. Realizar uma análise sociolinguística sobre o impacto das crianças estrangeiras na rede municipal de ensino;

b. Implementar, em conjunto com a SMED, ações de línguas (espanhol e inglês) no ensino fundamental da rede pública;

c. Preparar, ao final, a escola, bem como a comunidade que a compõe, para a importância de promover, por meio da educação, formas mais respeitosas e solidárias de convivência que diminuam as distâncias entre nós e os que consideramos como outros.

A partir desses objetivos e levando em consideração o acordo assinado, a equipe de pesquisadores(as) do Grupo de Pesquisa Linguagem, Política e Cidadania elaborou o

\footnotetext{
${ }^{1}$ Mais adiante, explicitaremos o embasamento teórico que respalda a escolha pelo termo "língua adicional" nesse contexto de pesquisa.

${ }^{2}$ Projeto 2599-2020, aprovado de acordo com os procedimentos institucionais estabelecidos pela Resolução n. 04/2018/COSUP e pela Instrução Normativa n. 05/2020/PRPPG.

${ }^{3}$ Coordenado pelas Professoras Jorgelina Tallei e Laura Amato (UNILA).

Revista X, v. 16, n. 3, p. 961-984, 2021. 
projeto que embasaria as ações junto à $\mathrm{SMED}^{4}$. Dentre as ações previstas, determinadas pelos objetivos do acordo, destacamos a formação continuada ${ }^{5}$ para docentes da rede municipal de ensino fundamental, prioritariamente docentes graduados(as) em Letras Espanhol e/ou Letras Inglês e com atuação no ensino fundamental. A formação continuada teve início em 2018 e objetivou trabalhar aspectos interculturais relacionados ao acolhimento, em contexto fronteiriço, das crianças internacionais ${ }^{6}$ matriculadas na rede de ensino. No ano de 2019, a formação continuada enfocou muito mais o aspecto intercultural e de fronteira, trabalhando conceitos fundamentais, como bilinguismo, contexto transfronteiriço e pluriculturalidade ${ }^{7}$. O curso de formação constituiu um processo de aprendizagem constante, a partir do compartilhamento de conhecimentos e reflexões com colegas e, principalmente, com professores(as) da rede municipal de Foz do Iguaçu.

Outro aspecto relevante a destacar é que o curso de formação fez parte de um conjunto mais amplo de ações voltadas à implementação de políticas linguísticas locais e regionais que têm buscado contemplar o contexto plurilíngue e multicultural no qual estamos inseridos. Nesse sentido, reforçamos que o sucesso do curso só foi possível porque estava articulado a outras ações: 1) o Programa Institucional Agenda Tríplice ${ }^{8}$, que estabeleceu um compromisso da UNILA com demandas específicas da comunidade externa - no caso, o processo de implementação de políticas linguísticas voltadas à diversidade; 2) a articulação com os grupos de pesquisa Linguagem, Política e Cidadania (UNILA) e Língua Estrangeira, Discurso e Identidade (USP); 3) o projeto de pesquisa sobre o currículo em contextos educacionais multilíngues e translíngues (FORTES, 2016a); e 4) as orientações de dois estagiários do curso Letras em uma escola municipal,

\footnotetext{
${ }^{4}$ Cf.: UNILA/UNIOESTE/IFPR, 2018.

${ }^{5}$ A formação continuada nos anos de 2018 e 2019 foi registrada como ação de extensão da UNILA com o seguinte título: Formação intercultural para docentes do Ensino Fundamental I: educação delem línguas na fronteira.

${ }^{6}$ Optamos pelo termo "internacionais", uma vez que compreendemos que não são "estrangeiras", considerando a nacionalidade (na sua maioria paraguaias).

${ }^{7}$ Mais adiante, alguns desses conceitos serão situados, considerando o escopo teórico adotado e as experiências de ensino relatadas neste texto. Por ora, apenas ressaltamos que os cursos ministrados no âmbito do Projeto partiram da noção de "interculturalidade crítica" proposta por Walsh (2012), que busca construir "outros modos de poder, saber, ser e viver" (WALSH, 2012, p. 11), articulando-se ao que a pesquisadora denominou "pedagogia decolonial".

8 "O Programa Institucional Agenda Tríplice tem como escopo estimular a realização de projetos de pesquisa de modo indissociável do ensino e da extensão, e que visem o estudo e o provimento de soluções para temas prioritários da tríplice fronteira Brasil, Argentina e Paraguai". Disponível em: https://portal.unila.edu.br/prppg/pesquisa/programas/agenda-triplice. Acesso em: 21 mar 2020.
}

Revista X, v. 16, n. 3, p. 961-984, 2021. 
contemplando uma demanda específica da SMED quanto a uma estudante internacional cuja língua materna era o inglês.

Trazendo essas reflexões para uma ampliação do recorte deste trabalho, consideramos também pertinentes as implicações históricas das políticas linguísticas do ensino de línguas no Brasil, marcadas por um percurso de políticas mais plurilíngues para políticas mais monolíngues, o que contribuiu para a constituição de uma memória discursiva em torno da presença do inglês na educação básica brasileira (FORTES, 2016b; 2019).

Como forma de construir possíveis contradiscursos, a inclusão, já nos anos iniciais do ensino fundamental, de oportunidades de aprendizagem de línguas que contemplem o compromisso com o plurilinguismo e com a democratização do ensino poderiam superar, assim, uma das contradições produzidas pela ausência de políticas públicas para o ensino de línguas adicionais nos anos iniciais de escolarização no Brasil, como aponta Gimenez (2010):

[...] uma contradição entre a oferta cada vez mais precoce da língua inglesa a crianças que integram o sistema de ensino e os preceitos que embasam a definição curricular na educação infantil e os primeiros 5 anos do ensino fundamental. Essa contradição se expressa na inserção, já há algum tempo, pelo setor privado, da língua inglesa nos anos iniciais de escolarização. Isso indica que as decisões curriculares podem ser afetadas não apenas pelas recomendações de câmaras técnicas de órgãos educacionais, mas também pelos ditames do mercado . (GIMENEZ, 2010, p. 14-, 15).

Considerando os contextos delineados na proposta pedagógica em questão (UNILA/UNIOESTE/IFPR, 2018), é importante destacar que, em um estudo recente sobre o ensino de inglês na educação pública brasileira, o Conselho Britânico fez um levantamento das propostas dos professores(as) para políticas públicas e sistema de ensino, dentre as quais se destaca o início do ensino do inglês como língua adicional no Ensino Fundamental - Anos Iniciais (BRITISH COUNCIL, 2015, p. 38). Em outro estudo, Batinga Agra e Ifa (2018) voltam-se à análise de uma experiência de implementação do ensino da língua inglesa no currículo de uma turma do Ensino Fundamental I de uma escola pública da periferia de Maceió, Alagoas. A partir da perspectiva teórica de multiletramentos, com foco no desenvolvimento da criticidade, os autores enfatizaram a relevância da inclusão do ensino de inglês nas séries iniciais do ensino público, pois, por meio do ensino da língua, foi possível problematizar e refletir sobre temas que viabilizaram tanto o desenvolvimento linguístico quanto "uma compreensão expandida 
do mundo, pois [os(as) alunos(as)] conseguiram ir além das visões homogeneizadoras e centralizadoras apresentadas inicialmente" (BATINGA AGRA; IFA, 2018, p. 28).

Por sua vez, a articulação do projeto de pesquisa com o curso de formação mencionado anteriormente possibilitou um desdobramento importante: a oferta, de modo experimental, de um curso de inglês para estudantes do Ensino Fundamental - Anos Iniciais da Escola Municipal Irio Manganelli, e de um curso de espanhol para estudantes do Ensino Fundamental - Anos Iniciais da Escola Municipal Arnaldo Isidoro de Lima, ambos com enfoque teórico-metodológico intercultural/discursivo. Para a concretização dos cursos, foram estabelecidas diversas etapas de trabalho envolvendo as seguintes dimensões: interinstitucional, administrativa, logística, acadêmica, pedagógica, política e didática. Por meio de reuniões presenciais e a distância, a equipe discutiu e planejou o currículo-base do curso ${ }^{9}$, levando em consideração os conteúdos interdisciplinares, as línguas/sujeitos em contexto de fronteira e as possibilidades de experiências de interculturalidade. A partir da análise de conteúdos e gêneros trabalhados pelas diferentes disciplinas dos Anos Iniciais do Ensino Fundamental, elaboramos a proposta interdisciplinar de ensino de inglês, cujo tema orientador foi "identidade e diversidade".

O projeto para os $1^{\circ} \mathrm{s}, 2^{\circ} \mathrm{s}$ e $3^{\circ} \mathrm{s}$ anos (The Iguassu Falls Legend) teve como tema a releitura da lenda das Cataratas do Iguaçu, enquanto o projeto para os $4^{\circ}$ s e $5^{\circ}$ s anos (Foz do Iguaçu Through My Eyes) se dedicou à relação do sujeito com seu entorno escola, bairro, comunidade, cidade. Considerando o curso como parte desses processos educacionais complexos, na busca da articulação ensino/pesquisa/extensão, foi possível estabelecer um diálogo importante entre os(as) participantes do projeto e a comunidade externa - estudantes, professores(as) e gestores(as) educacionais.

\section{PRESSUPOSTOS TEÓRICO-METODOLÓGICOS}

Um dos principais objetivos do projeto de pesquisa (FORTES, 2016a) foi compreender as relações discursivas que se constituem nas diversas práticas pedagógicas significadas pelos currículos de línguas na educação básica em contextos educacionais plurilíngues e multilíngues. Embora os termos "plurilíngues" e "multilíngues" sejam,

\footnotetext{
${ }^{9}$ A partir de reuniões pedagógicas e administrativas com a direção e coordenação da escola, foram formadas 4 turmas ( 2 matutinas e 2 vespertinas), com 20 vagas cada, com carga horária total de $20 \mathrm{~h}$ por turma, contemplando alunos do $1^{\circ}$ ao $5^{\circ}$ ano. Os(as) principais ministrantes do curso foram estudantes de Letras Inglês/Português, sob orientação de docentes e estudantes de pós-graduação vinculadas(os) às instituições participantes do projeto. Os detalhamentos sobre o curso serão apresentados mais adiante.
} 
muitas vezes, usados de modo intercambiável, no âmbito das discussões do projeto, tomamos a distinção entre os termos "plurilinguismo" e "multilinguismo" a partir das definições apresentadas na Carta Europeia do Plurilinguismo ${ }^{10}$, redigida pelo Observatório Europeu do Plurilinguismo: enquanto o plurilinguismo é definido como "a utilização de várias línguas por um indivíduo", o multilinguismo configura "a coexistência de várias línguas num grupo social". Desse modo, o plurilinguismo constitui uma abordagem que considera os sujeitos em suas relações com diversas línguas em determinado contexto social; por outro lado, o multilinguismo compreende a diversidade de línguas em uma sociedade, evocando, na maioria das vezes, a noção de indivíduos monolíngues, cujas línguas não entram em relação/contato.

Quanto à noção de currículo mobilizada pela pesquisa, considerando sua dimensão discursiva, concebemos o currículo como um instrumento linguístico, ou seja, um construto histórico-político que descreve e instrumentaliza os saberes sobre a língua e seu ensino, dando-lhes uma forma, uma interpretação, um recorte, uma organização (FORTES, 2016b). Tal instrumentalização não trabalha apenas (os saberes sobre) a língua, mas também produz efeitos sobre a relação sujeito-língua. Isso significa pensar a língua e o ensino em suas relações com determinadas condições históricas, políticas e econômicas que trabalham os sentidos sobre essa língua, produzindo determinadas representações de nacionalidade, de cultura, de sujeito. Desse modo, a pesquisa buscou desenvolver reflexões que contribuíssem para a construção de saberes em torno do currículo, produzindo possibilidades de deslocamentos de determinadas posições subjetivas impostas pelas diversas práticas e sentidos que afetam o trabalho docente, tais como: elaboração de materiais didáticos, práticas pedagógicas, processos formativos e políticas de línguas.

Entendemos que essa temática se torna cada vez mais pertinente no processo de aproximação à diversidade linguístico-cultural da região trifronteiriça de Foz do Iguaçu. Além da experiência do trânsito entre línguas e culturas nas fronteiras geográficas estabelecidas entre Foz do Iguaçu e Ciudad del Este (Paraguai) e entre Foz do Iguaçu e Puerto Iguazu (Argentina), os sujeitos que aqui vivem também estão em contato com a diversidade trazida tanto pela migração quanto pela imigração de mais de 90 etnias (UNILA, 2019, p. 14). Na cidade, deparamo-nos não apenas com diversas línguas, que seriam tradicionalmente identificáveis como unidades, mas também com diferentes “espaços de enunciação", em que as línguas "se dividem, redividem, se misturam, se

10 A Carta está disponível em: https://observatoireplurilinguisme.eu/images/Charte/ Charteplurilinguisme_ptV2.13.pdf. Acesso em 01 mai. 2021. 
desfazem, transformam por uma disputa incessante" (GUIMARÃES, 2002, p. 18). Ao cruzar a fronteira geopolítica entre Foz do Iguaçu e Ciudad del Este, deparamo-nos com a diversidade de espaços de enunciação perpassados por línguas como o espanhol, o português, o guarani, o jopara ("mescla", em guarani, em referência à "mistura" entre o espanhol e o guarani no Paraguai) e o portunhol (espaço de enunciação fronteiriço BrasilParaguai). Do outro lado da fronteira, em Puerto Iguazu, as interações fazem emergir, eminentemente, o português, o espanhol e o portunhol, mas a presença de indígenas guaranis em alguns locais faz ressoar sua língua e sua cultura, num contraste constante com as lojas do pequeno centro comercial da cidade.

No âmbito escolar, tais diferenças exigem políticas educacionais que deem mais visibilidade à diversidade, construindo relações de integração e cooperação solidária. Em uma região fronteiriça, o ensino de línguas nas escolas municipais é de fundamental importância.

No caso das escolas municipais de Foz do Iguaçu, no âmbito do Ensino Fundamental I, segundo dados disponibilizados pela Secretaria Municipal de Educação, há atualmente 372 (trezentas e setenta e duas) crianças estrangeiras matriculadas em quarenta e uma (41), das cinquenta e uma (51) instituições municipais de ensino (RIBEIRO, 2018, p. 954).

Os dados preliminares de um levantamento realizado em 2019 pelo Grupo de Pesquisa em parceria com a SMED indicam que esse número chegou a 568. Esses estudantes são provenientes do Paraguai, Argentina, Colômbia, Espanha, Japão, Estados Unidos, Síria, Peru, México, França, entre outras nacionalidades. Nesse contexto ${ }^{11}$, o projeto vinculado ao Acordo de Cooperação buscou construir uma ampliação do espaço das línguas adicionais na escola pública, com atenção especial para a língua espanhola, mas sem deixar de considerar o contexto multilíngue em questão.

Vale lembrar que, ao adotarmos a terminologia "línguas adicionais", buscamos uma aproximação com a concepção de ensino e aprendizagem de línguas como processos de construção de repertórios, possibilitando a compreensão de suas funções sociais, políticas e identitárias. Nesse sentido, tomamos como base a discussão epistemológica crítica de Jordão (2014) sobre as concepções de língua que perpassam as diversas designações (tais como "língua franca", "internacional", "global", "estrangeira"

${ }^{11}$ Ressalte-se que tal fato corrobora, por exemplo, o expressivo interesse das comunidades escolares (docentes/estudantes) de Foz de Iguaçu nos diversos projetos de extensão ofertados pela UNILA, UNIOESTE e IFPR. 
e "adicional"). Assim, do mesmo modo que o contato com a língua espanhola desde os anos iniciais do ensino fundamental constitui um fator importante no processo de socialização da criança, o contato com a língua inglesa também visa propiciar a ampliação de seu repertório linguístico (BLOMMAERT; BACKUS, 2011), ou seja, um conjunto de práticas de linguagem que ultrapassam a noção de língua como um sistema, envolvendo gêneros, estilos, práticas e discursos mobilizados como parte das interações comunicacionais nas quais a criança se insere diariamente.

Considerando essa visão de língua como prática social, é importante ressaltar que a língua inglesa atualmente é utilizada em situações envolvendo falantes de diferentes línguas maternas, colocando em xeque o conceito do "falante nativo". Desse modo, a noção de ELF (English as a lingua franca) - ou ILF (Inglês como Língua Franca), em português -, parece ser a mais adequada para refletir sobre questões de interculturalidade e diversidade linguística, produzindo aproximações com a noção de repertórios linguísticos mencionada anteriormente.

\begin{abstract}
Qualquer língua opera, essencialmente, em um contexto social que, por sua vez, sofre influência direta da cultura em que está inserida. No caso de uma língua franca com as características atuais do inglês, o diálogo entre culturas se faz cada vez mais premente, uma vez que, além dos falantes não-nativos, são também incluídos falantes dos círculos central e externo, perfazendo uma população de dois bilhões de falantes aproximadamente nos mais diversos níveis de proficiência, que vêm participando desse processo de forma cada vez mais ativa e marcadamente diversificada (SIQUEIRA, 2011, p. 100).
\end{abstract}

Nesse debate, a pedagogia do ILF se insere como um caminho construído em uma base de sensibilização intercultural, voltada à integração e à formação cidadã, considerando as complexidades do contexto trifronteiriço de identidades plurais que partilhamos. Compreende-se, diante do status de ILF neste contexto de implementação de línguas no currículo do Fundamental - Anos Iniciais, a necessidade de valorização do plurilinguismo, que, conforme definimos anteriormente, considera a diversidade de línguas a partir da dimensão dos sujeitos nas suas relações com as línguas, distanciandose do "paradigma monolíngue" (CANAGARAJAH, 2013).

Em articulação com tais conceitos, temos buscado, em nosso trabalho, uma aproximação à noção de "translinguagens" (CANAGARAJAH, 2011) como conceitualização que norteia a visão linguística para o ensino-aprendizagem, uma vez que este conceito abrange o leque de práticas tanto plurilíngues como multilíngues. Canagarajah (2013) analisa novos modos de comunicação - que não se pautam nas 
unidades linguísticas, mas no espaço de contingência das interações - como "práticas translíngues" [translingual practices], marcando uma mudança de paradigma na concepção de comunicação: de uma visão predominante monolíngue para uma visão "translíngue", segundo a qual "a comunicação transcende as línguas individuais" (CANAGARAJAH, 2013, p. 6). No mesmo sentido, considerando a conceitualização de práticas translíngues, adota-se, em termos pedagógicos, a perspectiva de um sujeito que não somente contribui para novas formas de comunicação, mas também novas formas de enriquecer o processo de ensino-aprendizagem.

Assim, concebem-se os participantes desse projeto enquanto ensinantes e aprendentes, que, na perspectiva de Fernandez (2001), constituem papéis que se alternam entre os interlocutores em uma situação propícia para ensinar e aprender. Desta maneira, ensinante não é sinônimo de professor(a) e aprendente não é sinônimo de aluno(a), mas compõem os indivíduos a partir de seus posicionamentos subjetivos e singulares frente ao conhecimento, que vão além da esfera escolar, e designam na linguagem cotidiana as funções de ensinar e de aprender em alternância nas interações.

\section{DESENHANDO O MATERIAL DIDÁTICO DO PROJETO}

A partir de uma política linguística horizontal, isto é, em colaboração entre a universidade pública (UNILA, UNIOESTE e IFPR) e o governo municipal (SMED) fez-se necessária a elaboração de recursos para a implementação de fato dessa política, de modo piloto, no currículo do Ensino Fundamental Anos Iniciais do município de Foz do Iguaçu. A partir da proposição do projeto, as entidades envolvidas articularam um currículo experimental para as turmas que seriam contempladas com as aulas de inglês; formaram um grupo de ensinantes, composto por acadêmicos(as) de Letras Português/Inglês, mestrandos (na área de Ensino e de Sociedade, Cultura e Fronteiras) e professores(as) universitários(as), que seriam responsáveis pela implementação de fato do ensino da língua na escola escolhida e, por fim, reuniram-se semanalmente para a elaboração dos recursos didáticos adotados.

As atividades do projeto foram oferecidas a crianças matriculadas na Escola Municipal Irio Manganelli, localizada no bairro Morumbi I, na região leste de Foz do Iguaçu. A coordenação da escola elaborou um bilhete comunicando aos pais a respeito do projeto e os que se demonstraram interessados preencheram a ficha de matrícula presencialmente na secretaria da escola. Foram abertas duas turmas no período da manhã e duas no período da tarde, cada uma com o total de 20 vagas, divididas de acordo com 
a faixa etária: duas turmas com alunos(as) de $1^{\circ}$ a $3^{\circ}$ ano e outras duas com alunos(as) de $4^{\circ}$ e $5^{\circ}$ ano do Ensino Fundamental - Anos Iniciais.

O desenvolvimento do material didático utilizado deu-se a partir de reuniões semanais entre os participantes do projeto. Nessas situações, refletimos a respeito dos aspectos linguísticos que seriam ensinados, considerando a faixa etária dos(as) alunos(as), e buscamos relacionar diferentes gêneros textuais com elementos interculturais significativos para as crianças fronteiriças. Assim, buscou-se desenhar materiais que pudessem atender à concepção de ensino de línguas enquanto prática translíngue, como proposto nesta investigação.

Como exemplo, citamos o conteúdo criado para a turma de $1^{\circ}$ a $3^{\circ}$ ano, que partiu de uma lenda local, a Lenda das Cataratas. Essa história, já presente no repertório das crianças, foi trabalhada em todas as aulas, fazendo-as deduzir o vocabulário (native people, food, animals, nature) e trazendo reflexões a respeito dos povos indígenas. Evidenciamos, por meio desta atividade (Figura 1), uma oportunidade de propiciar o desenvolvimento de aspectos translinguísticos considerando a relação que a cidade pode se dar em termos de cultura e relação com a língua. A sequência didática proposta culminou com a visita de estudantes universitárias indígenas pertencentes à etnia Tikuna ${ }^{12}$, que protagonizaram a aula discutindo aspectos de seus modos de vida na comunidade de origem e na universidade, de sua cultura e de sua língua, engajando os(as) estudantes em práticas interculturais e translíngues (Figura 2).

Incentivou-se esse tipo de prática neste contexto pedagógico, pois os(as) alunos(as) puderam participar de usos de língua em sua dimensão social e, ao mesmo tempo, refletir sobre as relações que permeiam a língua inglesa e a língua portuguesa no léxico relativo a animais encontrados na região e/ou que constituem o imaginário configurado a partir da (des)construção constante da narrativa-base (lenda das Cataratas), especialmente com relação às representações dos povos indígenas. Desse modo, foram criados flashcards, fantoches, fantasias para role-play, worksheets, jogos e apresentações de Powerpoint e Prezi, estas últimas apresentadas em uma sala específica da escola que possui multimídia.

Outro exemplo concernente aos materiais didáticos refere-se à aula para $4^{\circ} \mathrm{e}$ $5^{\circ}$ anos, parte da sequência didática do projeto Foz do Iguaçu through my eyes, cujo objetivo era o de conduzir pedagogicamente os alunos(as) para se situarem no mundo, enfocando a relação de sujeito com o seu entorno (escola, bairro, comunidade, cidade

\footnotetext{
${ }^{12}$ Nekinha Moçambite Coelho e Jhine Flores Peres, acadêmicas indígenas da UNILA (curso de Antropologia de Ciências Econômicas, respectivamente).
} 
etc.). A condução de uma das atividades referentes a essa sequência didática seria feita por meio de uma apresentação preparada em Prezi, com ênfase em directions, a qual não se mostrou exitosa, por incompatibilidade com os instrumentos disponíveis pela escola. Entretanto, o uso da tecnologia motivou o desenho dos materiais em si, pois sua confecção foi realizada por meio da ferramenta Canva, que permitiu criar uma série de atividades e pôsteres na perspectiva de gêneros textuais. Desse modo, partimos para a proposta de atividades que pudessem ser confeccionadas pelos próprios estudantes, tanto em sala de aula quanto no pátio da escola.

A atividade do mapa interativo (Figura 3) procurou desenvolver a capacidade do(a) aluno(a) de se situar, (e reconhecer os locais como restaurante, farmácia etc.) desde onde ele(a) se encontrava até os diferentes lugares ao redor da escola e do bairro. O processo de criação se deu inicialmente na tentativa de engajar os(as) alunos(as) em uma aula externa e mais interativa. Em uma das reuniões pedagógicas semanais, discutimos sobre o assunto e desenvolvemos um tapete em forma de mapa interativo, para que os(as) alunos(as) reconhecessem o espaço da escola - priorizando os estabelecimentos ao seu redor - e, em seguida, criassem seu próprio bairro com as tags nomeadas com locais populares encontrados na cidade (escola, farmácia, restaurante, igreja etc.). Por meio dessa atividade, foi possível trabalhar o cotidiano já existente na vida dos(as) alunos(as) juntamente com a temática na língua adicional.

Figura 1: Atividade Iguassu Falls Animals.

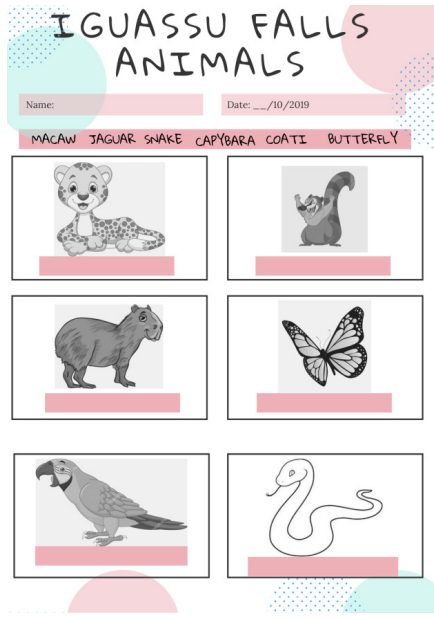

Fonte: Recurso didático elaborado pelos autores usando a ferramenta Canva.
Figura 2: Visita de estudantes universitárias indígenas.
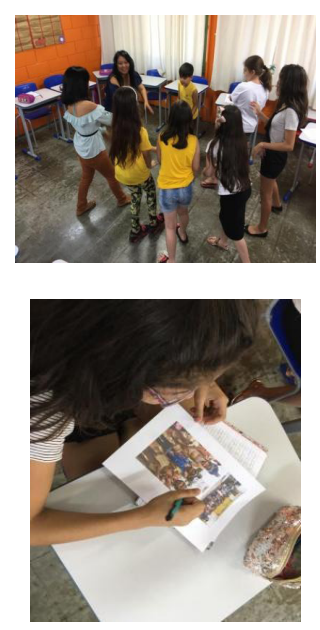

Fonte: Arquivo fotográfico do Projeto.
Figura 3: Atividade do mapa interativo.

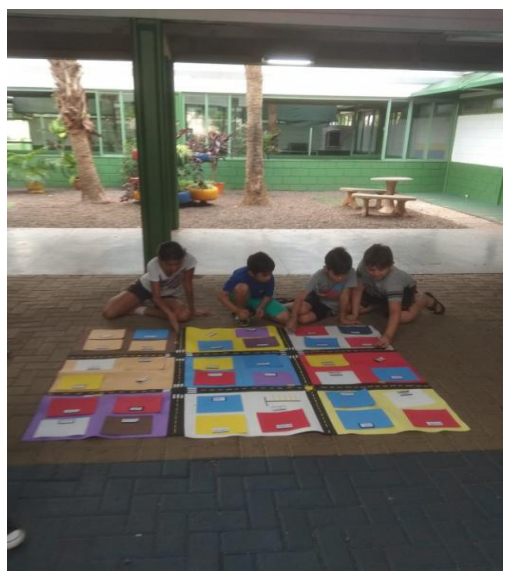

Fonte: Arquivo fotográfico do Projeto. 
O tapete (Figura 3) foi construído com a junção de 19 E.V.A.s, sendo 9 inteiros, 9 cortados em 4 partes e 1 para fazer o efeito de "ruas do bairro". O restante do material (retalhos) foi usado para outros efeitos, tais como as faixas de divisão das ruas, faixas de pedestre, pontos de ônibus etc. $\mathrm{O}$ velcro foi a peça-chave para que fosse possível alterar os locais e (re)colocá-los fixados em determinado ponto do mapa e o papel sulfite com os nomes impressos (e de tamanhos razoáveis) no computador, recortados e colados em cada tag.

Para a execução da atividade, a professora (ensinante) separou igualmente as fichas para cada aluno(a). Fizeram um círculo ao redor do tapete, e o primeiro aluno em sentido horário foi o escolhido para iniciar a montagem. Ele teria que escolher um(a) colega para ler em voz alta a palavra escrita na ficha que estava nas mãos de quem o escolheu e questioná-lo onde se encontra tal estabelecimento. Em seguida, o(a) outro(a) aluno(a) responde e independente da resolução (certa ou errada), prossegue dando um exemplo conhecido preferencialmente em torno da escola e, assim, sucessivamente. Durante o processo, percebeu-se a ajuda mútua entre os(as) colegas para reconhecer os diferentes espaços que cercam o ambiente escolar, assim como a criatividade para que uma nova arquitetura dos estabelecimentos do bairro fosse pensada em conjunto. Dessa forma, o papel da professora foi o de instruir, acompanhar, orientar e certificá-los(las) sobre suas respostas no decorrer da atividade.

Assim, percebeu-se que a confecção de materiais é fruto de um grande trabalho de relação entre planejamento e prática, que visa a atender as demandas de um ensino crítico de línguas, e que ainda seja lúdico e adequado para a faixa etária trabalhada. Da criação até a implementação, almejou-se uma reflexão crítica de boas práticas e práticas a serem melhoradas. Contempla-se essa autoavaliação de forma mais centrada na ensinante, que, enquanto acadêmica de Letras, pôde aprofundar suas reflexões por meio de perspectivas de conexão entre material, teoria e prática, no que tange o processo de ensino-aprendizagem de línguas adicionais para crianças.

\section{PROCESSOS FORMATIVOS DOS(AS) ENSINANTES-APRENDENTES}

Para lecionar no curso de inglês como língua franca às turmas do Ensino Fundamental - Anos Iniciais da Escola Municipal Irio Manganelli, formou-se um grupo heterogêneo, composto por docentes, acadêmicos e pós-graduandos da UNILA, do IFPR de Foz do Iguaçu e da Unioeste de Foz do Iguaçu, os quais são mencionados aqui como ensinantes. Atuar no projeto Pedagogia Intercultural: ensino de línguas no ensino fundamental trouxe aos(às) ensinantes uma possibilidade de refletir acerca de uma Revista X, v. 16, n. 3, p. 961-984, 2021. 
importante questão que perpassa todas as implicações do processo de ensino-aprendizagem de língua adicional, no que tangem os aspectos fundamentais da práxis docente.

Por intermédio da participação ativa dos(as) ensinantes ${ }^{13}$ em todo o processo de planejamento, discussão e análise de conteúdos, das aulas e a transposição didática, e da reflexão posterior às aulas, foi possível identificar que existe uma lacuna entre a formação do(a) pedagogo(a) e a formação do(a) docente de Letras, quando se trata de ensino de línguas para crianças da educação infantil e dos anos iniciais do ensino fundamental, uma vez que o(a) pedagogo(a) não recebe formação para o desenvolvimento e aplicação de metodologias de ensino de língua e, tampouco, o(a) licenciado(a) em Letras tem formação sobre o desenvolvimento infantil e os métodos de letramento adequados a esta etapa da vida escolar. Em consonância com os preceitos teóricos adotados neste trabalho, consideramos os processos de letramento em sua imbricação com práticas translíngues, uma vez que se trata de um processo dinâmico pelo qual os sujeitos (re)constroem seus repertórios semióticos (cf.: GARCIA; KLEIFGEN, 2020).

Durante nossos encontros de planejamento de aulas, foi possível, numa atividade interdisciplinar e multicolaborativa, constatar essa defasagem entre as formações, já que os(as) acadêmicos(as)-ensinantes eram discentes do curso de Letras e tiveram que observar muitas questões sobre meios de transposição para articular os conteúdos, pensando sempre na capacidade proficiente das crianças, sobretudo, na leitura e na escrita.

Diante desta problemática, nossa participação no projeto revelou que ainda há muitos desafios para gerar meios adequados de inserir o ensino de línguas adicionais nos anos iniciais do ensino fundamental e, também, que é somente pela aliança entre a escola, a comunidade e a atividade de pesquisa acadêmica e multidisciplinar que será possível delinear uma proposta de inserção de línguas nessa etapa da vida escolar, visto que se deve analisar minuciosamente cada ação pedagógico-metodológica para que a transposição dos conteúdos seja adequada e salutar para a cognição das crianças, além de garantir que essa vivência seja plural e assegure a integridade da sua dignidade.

\footnotetext{
${ }^{13}$ Atuaram como ensinantes do projeto: a professora doutora Laura Fortes, da Unila, líder da frente da língua inglesa no projeto Pedagogia Intercultural: ensino de línguas no ensino fundamental; a professora mestra Márcia Pessini e a acadêmica Ana Lúcia Kurtz Aristides, aluna do $3^{\circ}$ ano do Curso Técnico em Informática do Ensino Médio do IFPR - Foz do Iguaçu; a professora mestre Renata Alves de Oliveira e os acadêmicos do curso de Letras com habilitação em Português e Inglês Ellyane da Rosa ( $1^{\circ}$ ano), Isabella Cristina Haruna Murakami ( $3^{\circ}$ ano), Luis Eduardo Pereira Santos ( $3^{\circ}$ ano), Maria Clara da Silva Borba e Maria Karolina da Silva Tavares ( $1^{\circ}$ ano) da Unioeste - Foz do Iguaçu; a mestre Etiene Mello da Unioeste - Foz do Iguaçu; Os mestrandos da Unioeste - Foz do Iguaçu: João Lucas Cavalheiro Camargo e Lívia Cristina Carvalho da Fonseca. Revista X, v. 16, n. 3, p. 961-984, 2021. 
Nosso papel no projeto era focado em ativar a percepção dos(as) ensinantes sobre algumas questões importantes, tais como tornar o conhecimento concreto e articular as abstrações com ludicidade. Na transposição didática, intentamos proporcionar um campo visual adequado (como quadro, letra, figuras, desenhos etc.), na ordem direta e de modo organizado, em que a criança pudesse reconhecer início, meio e fim das palavras e sentenças, associando imagens a palavras. Nosso enfoque nas reuniões de planejamento teve como prioridade atentar para o insumo que os(as) alunos(as) apresentavam ao longo das aulas, às demandas dos(as) alunos(as) em relação às temáticas trabalhadas, ao tempo de explanação, transposição, argumentação, cópia e verificação do feedback das crianças. Intuímos ser necessário fazer revisões contínuas e progressivas, sempre observando se a lógica da sequência didática era compreendida pelas crianças. Também a adaptação do conteúdo às particularidades dos grupos foi uma abordagem constante do grupo ensinante, já que tomamos especial cuidado para não traçar conceitos com base em estigmas e estereótipos relacionados às culturas, às línguas, aos modos de viver e interagir, às representações dos povos etc.:

quando se trata do ensino de línguas pela abordagem intercultural, todos os indivíduos, independentemente da etnia, da cultura e da língua, devem ser considerados sujeitos atuantes e praticantes da conscientização da diversidade. Deve-se buscar a criticidade para que o ensino da LE não se torne uma divagação baseada em uma noção superficial, estereotipada, discriminatória, ingênua e/ou preconceituosa da língua/cultura-alvo. Para isso, é preciso que o professor esteja comprometido com o objetivo de tornar o aluno apto a se tornar um indivíduo crítico-consciente (OLIVEIRA, 2012, p. 62).

Desde o primeiro encontro, houve orientação e despertar para situações próprias da prática, como por exemplo, o diagnóstico geral das turmas, dentre outras questões que só poderiam ser definidas depois que se conhecesse o público alvo. Assim, os acadêmicos-ensinantes puderam compreender que a proposta não partia de um pacote préestabelecido, mas de uma experiência que pudesse ser significativa para aqueles grupos. Somente depois de gerarem dados - quem eram os(as) alunos(as); que expectativas tinham naquele momento em que se iniciava o curso; como imaginavam que seriam as aulas; algumas questões relacionadas às comunidades de que participavam; o que sabiam sobre a língua-alvo; que relevância atribuíam a esta aprendizagem; por que integravam como alunos(as) do projeto -, é que partimos para as especificidades do método e da seleção do conteúdo. 
A distinção ensinante-aprendente (FERNANDEZ, 2001), não por acaso, permite-nos compreender a sala de aula não somente como um espaço para ensinar, mas substancialmente para aprender com os(as) alunos(as), que também alternam nas funções de ensinar e aprender, ainda que despropositadamente. Deste modo, as reflexões pré-aula e pós-aula foram extremamente relevantes para que pudéssemos, enquanto ensinantes, lidar com as limitações das nossas formações para lecionar para crianças das séries iniciais. Para lidar com esse défice, nossa atividade multi e interdisciplinar foi a substância que efetivou nossa ação. Os debates constantes sobre os avanços e os retrocessos do grupo a cada aula, as atitudes e a disponibilidade docente frente ao ensino de línguas para crianças; as ricas possibilidades de produção de materiais significativos; a escuta ativa e motivadora; todas as vivências nesse campo de atuação nos proporcionaram uma forma de pensar a prática docente por uma perspectiva de valorização e reconhecimento do conhecimento prévio das crianças aprendentes em relação aos conteúdos trabalhados, buscando sempre partir de uma noção comum aos grupos e ensinar movidos por um senso de reciprocidade na construção de conhecimentos. E, diante de todas as problematizações que apuramos ao longo de todo o processo, concebemos que:

a criança deve ser compreendida como sujeito astuto, capaz de entender as funções da linguagem, utilizando-a de maneira adequada às suas reais necessidades. Ela é, também, capaz de articular seu conhecimento de acordo com as práticas sociais de que participa a fim de desempenhar seu papel como sujeito volitivo e atuante na situação de ensino-aprendizagem. Suas reações diante das informações que lhe são dirigidas podem refletir atos de astúcia bem como de estratégia, pois a criança é sujeito manipulador e consciente de suas habilidades e aptidões (OLIVEIRA, 2012, p. 65).

Diante dessa vivência na proposta piloto de inserir a língua adicional nos anos iniciais do ensino fundamental, depreendemos, como ensinantes, que é preciso fomentar a formação docente, sobretudo na deliberação de estratégias para calçar os défices que podem incidir como adversidades no processo de ensino-aprendizagem, para assegurar a dignidade da criança, seu lugar de fala, seu posicionamento diante das discussões nas aulas; entendendo-a como ente com potencial capacidade de aprender, portanto, compreendendo-a como aprendente, agente protagonista na construção do próprio saber. 


\section{INSERÇÃO DE DIFERENTES ESTRATÉGIAS DIDÁTICO-PEDAGÓGICAS QUE CONTRIBUAM PARA O PROCESSO DE ENSINO-APRENDIZAGEM}

Cada turma apresenta uma característica singular, desde suas ações e reações de forma conjunta até sua aprendizagem, assim como cada aluno(a) também se destaca em alguma habilidade (leitura, escrita ou oralidade) durante seu processo educacional. Com a experiência em sala de aula, percebe-se que, em algumas situações, o(a) aluno(a) desvia o seu foco para outras atividades, sejam elas de cunho material ou oratório, mesmo que a atividade aplicada corresponda a sua maior habilidade e/ou assunto de seu interesse. Para isso, estruturam-se planos alternativos e de ação para alunos(as) que apresentam dificuldades em foco e atenção, ou seja, adotam-se estratégias para que o(a) aluno(a) melhore o seu desempenho em alguma competência pouco explorada e se concentre nas atividades propostas utilizando ferramentas interativas e dinâmicas para o andamento de alguns exercícios durante as aulas.

No decorrer do projeto, os/as ensinantes adotaram tais planos de ação em sua prática pedagógica, a fim de atender a determinadas necessidades de aprendizagem dos/ as estudantes. Quando a criança-aprendente demonstrava alguma dificuldade para ler, escrever ou falar, espontaneamente, o(a) ensinante verificava em qual dessas áreas havia maior dificuldade de aprendizado. Assim, dava-se início à fase de arquitetar atividades que contribuíssem para impulsionar espontânea e positivamente tal competência, para que a criança-aprendente pudesse avançar em seu processo de aprendizagem. Relataremos alguns fatos que aconteceram durante o período lecionado, a partir de experiências vivenciadas em aula, enquanto ensinante, participante do projeto.

Logo no início do projeto, uma das crianças, que gostava muito das minhas aulas, interagia com os colegas na língua materna de forma autêntica, entendia o que eu falava, mas quando se tratava de alguma atividade em grupos, duplas ou trios, voltada para a conversação, seu semblante era receoso. Há muitas hipóteses para esse tipo de reação: por não ter entendido as instruções, pode ter focado em outras atividades durante a minha explicação; ou, porque seu desempenho fosse melhor na escrita e/ou leitura do que na fala.

Passado pelo estágio de observação no período de algumas aulas, certifiquei-me de que o seu maior obstáculo era a competência inexplorada de fala em língua adicional. Deste modo, reuni-me com os demais ensinantes e procuramos encontrar um plano de ação que fosse executado durante as aulas, mas que envolvesse os outros colegas, pensando em algo que transpassasse todos os níveis e não fosse excludente. Depois de várias discussões sobre as atividades, surgiu a ideia de fazer um pequeno mapa em tapete (exemplificado no tópico sobre os materiais didáticos elaborados) usando locais próximos Revista X, v. 16, n. 3, p. 961-984, 2021. 
ao colégio e, formulando perguntas como "Where is...?" e respostas usando direções (right, left, straight on, behind, etc.) e dimensões (It's far away from..., It's near..., closer, etc.). A forma dinâmica como a atividade foi trabalhada auxiliou no processo de fala do(a) aluno(a), uma vez que sua habilidade era explorada de forma alternativa, utilizando jogos e brincadeiras que potencializaram as suas diversas formas de expressão e de relação com a língua.

Outra criança-aprendente também aparentou ter as mesmas características e observações ditas anteriormente, exceto que suas maiores competências situavam-se na fala e na escrita. Na tentativa de melhorar a habilidade de leitura, foi proposto um Memory game utilizando a temática trabalhada na turma, no qual, para fazer a junção dos pares, seria necessário encontrar uma parte com a imagem e a outra, com seu significado (trabalhando a leitura verbal e não-verbal) e, caso o par fosse correto, deveria mostrar a imagem encontrada que se associava com a palavra composta no jogo e lê-la para a turma. Durante a preparação do jogo, a classe foi dividida em duas equipes, podendo alternar os participantes das equipes no fim de cada rodada. Na execução da atividade, a criança-aprendente em questão se envolveu e participou da atividade e também se voluntariou para ler as palavras.

Logo, entende-se que a inserção de diferentes estratégias de ensino auxilia na aprendizagem, pois proporciona maior interesse por parte da criança), explora de forma mais abrangente suas habilidades, trabalha as áreas de maior dificuldade de modo mais divertida e facilita o processo de input e output. O seguimento de atividades interativas faz com que a criança aprendente crie maior destemor durante o seu aprendizado e, de forma espontânea e inconsciente, amplifique seu conhecimento. Desse modo, o(a) professor(a) (ensinante) torna-se mediador(a) e permite que seus(as) alunos(as) (aprendentes) tenham maior abertura e autonomamente se ajudem, se questionem e trabalhem em conjunto para um melhor resultado.

\section{O ENSINO DE LÍNGUAS ADICIONAIS NAS SÉRIES INICIAIS E A PRO- BLEMATIZAÇÃO DA REALIDADE MULTILÍNGUE E MULTICULTURAL VIVENCIADA: UM OLHAR SINGULAR SOBRE O PROCESSO}

O IFPR é uma instituição federal composta por vinte e seis campi, entre eles, três são campi de fronteira - o campus Foz do Iguaçu é um deles. A partir dessa realidade, é imprescindível pensar a educação aqui trabalhada sob a especificidade da realidade linguística e cultural experienciada nesse contexto. Nesse sentido, para o IFPR e, especialmente, para o campus Foz do Iguaçu, fazer parte de um projeto que 
busca a implementação de línguas adicionais nas séries iniciais das escolas públicas do nosso município e a problematização da realidade multilíngue e multicultural vivenciada é fundamental.

Um dos pontos importantes a se descrever foi a forma como nos organizamos enquanto grupo para a organização do projeto, que foi desenvolvido por instituições diferentes que se uniram em busca de um objeto maior - introduzir o ensino de línguas para alunos(as) do Ensino Fundamental - Anos Iniciais das escolas públicas municipais de Foz do Iguaçu. A pertinência de tal objetivo nos faz crer que estávamos cumprindo nosso papel social e nosso dever enquanto educadores participantes de uma região de fronteira com uma realidade multilíngue e multicultural. Entretanto, esse foi um grande desafio para todos os envolvidos no projeto, já que a participação de várias instituições demandava muita organização. Neste espaço será relatada a maneira como nos organizamos, enquanto equipe de trabalho multi-institucional, para alcançarmos o objetivo almejado com o projeto.

É importante registrar aqui o quanto a tecnologia e o uso de ferramentas da internet foram fundamentais para o êxito do projeto, pois auxiliaram principalmente em sua organização geral. Elas aproximavam os integrantes do grupo, dando a possibilidade de que todos pudessem participar ativamente das discussões e planejamento, mesmo que a presença física nas reuniões de trabalho não fosse possível. Outro aspecto que merece destaque foi o fato de que os participantes do grupo definiram que as reuniões semanais fossem feitas em diferentes locais a cada semana, de maneira que todas as instituições envolvidas recebiam os demais participantes do projeto, o que facilitava a participação nas reuniões.

Como explicitado anteriormente, o projeto desenvolvia o trabalho em duas turmas - uma pela manhã e outra à tarde - e, em cada período tínhamos duas turmas separadas - uma destinada aos(às) alunos(as) provenientes do primeiro ao terceiro anos e a outra para os(as) alunos(as) do quarto e quinto anos. As etapas de trabalho eram geralmente organizadas semanalmente da seguinte forma: 1. reuniões pedagógicas voltadas ao planejamento e à elaboração/adaptação de materiais didáticos; 2. reuniões em grupos menores, para orientação dos(as) ministrantes-ensinantes de cada turma (que poderiam variar, de uma semana para outra); 3. ministração das aulas pelos(as) ensinantes, sempre acompanhados(as) do(a) orientador(a)-ensinante.

Foi, sem dúvida, um período de trabalho intenso e exaustivo, mas também de muito crescimento, tanto pessoal quanto profissional. Fazer parte de um projeto de tal envergadura, que apresenta essa importância para o nosso município, é motivo de muito 
orgulho e alegria para um profissional da área da linguagem que compreende a riqueza do ambiente sociolinguisticamente complexo no qual está inserido e uma pessoa que acredita que é possível e necessário contribuir para o desenvolvimento da sociedade da qual faz parte.

Ensinar inglês sempre foi motivo de grande entusiasmo em minha trajetória acadêmico-profissional, especialmente ensinar inglês para crianças, algo que trouxe imensa satisfação e alegria, pois seria a oportunidade de rememorar os lindos momentos em que fui professora de Educação Infantil e Ensino Fundamental. Só quem já teve o prazer de ter a experiência de ser professora para alunos(as) da primeira infância é que sabe a emoção que tais momentos nos reservam. Dar aula para crianças foi a experiência profissional mais prazerosa e inesquecível "do projeto", pois era algo que enchia meus dias de alegria e sensibilidade. Reviver essa experiência e ainda somada à possibilidade de ensinar língua inglesa foi, sem dúvida, a oportunidade de trabalho mais proveitosa durante o ano letivo.

O projeto foi pensado e desenvolvido a partir de uma perspectiva de sensibilização intercultural, possibilitando a integração linguística e cultural, tão fundamentais em um contexto trifronteiriço do qual partilhamos. Nesse sentido, é preciso falar sobre a especificidade do trabalho que tínhamos a intenção de desenvolver com a realização desse projeto - ensinar língua inglesa para alunos(as) da escola pública municipal em um contexto de tríplice fronteira sob a perspectiva da interculturalidade. Pretendíamos dar aos(às) alunos(as) oportunidades de experienciar, através da língua e da cultura do outro, momentos que permitissem interpretar novas realidades culturais e, assim, refletir sobre elas, tendo a possibilidade de analisá-las, a fim de compreender que é preciso conhecer e respeitar outras formas de interpretar o mundo, levando à reflexão sobre a diversidade cultural.

Partimos da compreensão de que cada falante estabelece um vínculo com o seu próprio idioma e que tal vínculo é construído socialmente desde a infância e vai se aprimorando ao longo da sua vida. Acreditamos, ainda, que o ensino de uma língua adicional à criança se fundamenta no conhecimento da língua materna e, a partir dessas prerrogativas, buscamos planejar o desenvolvimento do projeto e a organização didática das aulas. Planejamos ensinar a língua enquanto interação entre os sujeitos-aprendentes, visando muito mais do que o estudo linguístico, permitindo a reflexão em torno das culturas próximas à realidade das crianças, na região da tríplice fronteira, e, a partir daí, as suas identificações com a língua inglesa. Tal abordagem foi motivo de entusiasmo para os(as) alunos(as), pois foram incentivados a participar das discussões promovidas 
em aula, interagindo ativamente com a possibilidade de analisar suas vivências culturais a partir da análise de outras línguas-culturas, levando ao reconhecimento da diversidade que os constituía.

Foi notório o crescimento do interesse dos(as) alunos(as) pela aprendizagem da língua inglesa ao longo do projeto. Outro aspecto interessante a se relatar é a avaliação positiva de toda a comunidade quanto ao trabalho realizado. Éramos constantemente questionados se o projeto teria continuidade no ano seguinte e se os demais alunos(as) da escola (aqueles/as que não participaram durante esse ano) poderiam fazer parte. Tais fatos indicam o êxito do trabalho desenvolvido e, ao mesmo tempo, apontam a necessidade de que práticas como as que foram desenvolvidas ao longo do projeto - ou seja, o ensino de línguas adicionais sob a perspectiva de educação intercultural - tornem-se algo comum, especialmente no que se refere aos contextos de fronteira. Acreditamos, portanto, que a inclusão do ensino de línguas adicionais nas séries iniciais do ensino público é de total relevância, pois o contato com a outra língua e cultura do outro trouxe a possibilidade de problematizar a realidade multilíngue e multicultural vivenciada por esses(as) alunos(as) e assim levá-los a refletir sobre a diversidade na qual estamos inseridos(as).

\section{CONSIDERAÇÕES FINAIS}

A partir das experiências relatadas neste trabalho, buscamos contribuir com as discussões atuais sobre ações de implementação do ensino de línguas adicionais no Ensino Fundamental - Anos Iniciais, refletindo, sobretudo, a respeito da necessidade de construir políticas linguísticas e educacionais que contemplem:

a. a elaboração de materiais didáticos que atendam à demanda de um ensino crítico de línguas, organicamente vinculados às vivências de diversidade, com foco em práticas interdisciplinares, translíngues e lúdicas;

b. os processos de formação docente dos(as) ensinantes (sejam estudantes de Letras ou estudantes de Pedagogia) quando se trata de ensino de línguas para crianças, articulando conhecimentos sobre metodologias de ensino de língua a conhecimentos sobre o desenvolvimento infantil e os métodos de letramento adequados a esta etapa da vida escolar;

c. a inserção de diferentes estratégias didático-pedagógicas que contribuam para o processo de ensino-aprendizagem, considerando a(s) singularidade(s) da criançaaprendente em sua relação com a língua adicional enquanto prática translíngue; 
d. as práticas interculturais no ensino de línguas adicionais em contexto de fronteira, constituindo um processo dinâmico de compartilhamento, comunicação e aprendizagem de saberes e práticas (WALSH, 2012), com vistas à construção de um espaço de negociação no qual se reconhecem os conflitos para refletir sobre modos de intervenção solidária, contribuindo, assim, para o reconhecimento e valorização da diversidade.

Como procuramos demonstrar, essas e outras dimensões pertinentes ao processo de construção de políticas linguísticas e educacionais nos contextos aqui delineados podem ser compreendidas ao mobilizarmos o conceito de práticas translíngues (CANAGARAJAH, 2013). Esse conceito tem circulado no campo da Linguística Aplicada, estando especialmente vinculado a uma visão crítica, mais heterogênea, vinculada a concepções de língua distanciadas do paradigma monolíngue, a fim de pensar questões de ensino e de formação de professores(as), tais como Rocha e Maciel (2015) em seu artigo recente sobre o ensino de LE como prática translíngue; e Cavalcanti (2013), que discute a educação linguística na formação de professores(as) de línguas a partir da perspectiva teórica da intercompreensão e das práticas translíngues.

Assim, em consonância com as pesquisas citadas, os relatos de experiência compartilhados neste trabalho atestam a necessidade de democratizar o ensino de línguas adicionais nos anos iniciais do Ensino Fundamental por meio da implementação de políticas públicas, visando impactar positivamente diversos âmbitos das comunidades escolares de Foz do Iguaçu, tais como a formação de professores(as), a estruturação curricular, a elaboração de materiais didáticos e o aprimoramento das práticas pedagógicas interculturais e translíngues em contexto de fronteira.

\section{REFERÊNCIAS}

BATINGA AGRA, C.; IFA, S. Ensino de inglês para crianças nas séries iniciais do ensino público à luz dos multiletramentos. Letras \& Letras, [S.1.], v. 34, n. 1, p. 2847, jul. 2018. Disponível em: <http:/www.seer.ufu.br/index.php/letraseletras/article/ view/39036/22429>. Acesso em: 08 jul. 2018.

BLOMMAERT, J.; BACKUS, A. Repertoires revisited: 'Knowing language' in superdiversity. In: Working Papers in Urban Language \& Literacies. Paper 67, p. 1-26, 2011. 
BRITISH COUNCIL. O ensino de inglês na educação pública brasileira: elaborado com exclusividade para o British Council pelo Instituto de Pesquisas Plano CDE. São Paulo: British Council Brasil, 2015. Disponível em: <https://www.britishcouncil.org.br/sites/ default/files/estudo_oensinodoinglesnaeducaca opublicabrasileira.pdf $>$ Acesso em 07 jul. 2018.

CANAGARAJAH, S. Translanguaging in the classroom: emerging issues for research and pedagogy. Applied Linguistics Review, De Gruyter, v. 2, p. 1-28, 2011.

CANAGARAJAH, A. S. Translingual practice: global Englishes and cosmopolitan relations. New York and Abingdon: Routledge, 2013.

CAVALCANTI, M. C. Educação linguística na formação de professores de línguas: intercompreensão e práticas translíngues. In: MOITA LOPES, L. P. da (Org.). Português no século XXI: cenário geopolítico e sociolinguístico. São Paulo: Parábola, 2013. p. 211-226.

FERNÁNDEZ, A. Os idiomas do aprendente: análise de modalidades ensinantes em famílias, escolas e meios de comunicação. Porto Alegre: Artmed, 2001.

FORTES, L. Entre o silêncio e o dizível: um estudo discursivo de sentidos de bilinguismo, educação bilíngue e currículo em escolas bilíngues português-inglês. 2016. 444 f. Tese (Doutorado) - Faculdade de Filosofia, Letras e Ciências Humanas, Universidade de São Paulo, São Paulo, 2016a.

FORTES, L. O currículo como instrumento linguístico: ordem e organização de saberes em contextos educacionais multilíngues e translíngues. Projeto de Pesquisa. UNILA. Foz do Iguaçu, 2016b.

FORTES, L. Políticas de línguas e memória do ensino de inglês no Brasil: entre o silêncio e o dizível. In: Fotografias da política linguística na pós-graduação no Brasil.1 ed.João Pessoa: UFPB, 2019, v.1, p. 89-130. Disponível em: http:/www.editora.ufpb.br/sistema/ press5/index.php/UFPB/catalog/book/136. Acesso em 5 fev. 2020.

GARCIA, O.; KLEIFGEN, J. A. Translanguaging and literacies. Reading Research Quarterly. Volume 55, Issue 4. October/November/December 2020. p. 553-571.

GIMENEZ, T. Apresentação. In: ROCHA, C. H., TONELLI, J. R. A.; SILVA, K. A. da (Orgs). Língua estrangeira para crianças: ensino-aprendizagem e formação docente. Campinas, Pontes, 2010. p. 13-25.

GUIMARÃES, E. Enunciação e acontecimento. In: . Semântica do Acontecimento. Campinas, SP: Pontes, 2002. p. 11-32. 
JORDÃO, C. M. ILA - ILF - ILE - ILG: quem dá conta?. Rev. bras. linguist. apl., Belo Horizonte, v. 14, n. 1, p. 13-40, Mar. 2014. Disponível em: <http://www.scielo.br/ scielo.php? script=sci_arttext\&pid=S1984-63982014000100002\&lng=en\&nrm=iso $>$. Acesso em 6 jan. 2018.

OEP (Observatório Europeu do Plurilinguismo). Carta europeia do plurilinguismo. Jornadas Europeias de Plurilinguismo, 2005-2019. Disponível em: <https://www. observatoireplurilinguisme.eu/images/Charte/Charteplurilinguisme_ptV2.13.pdf.> Acesso em 23 mar 2020.

OLIVEIRA, R. A. Programa Escolas Bilingues de Fronteira: das generalizações do documento às especificidades da fronteira entre Foz do Iguaçu e Puerto Iguazu. Dissertação de Mestrado (Linguística) - Universidade Federal de São Carlos-UFSCar, 2012.

RIBEIRO, S. B. C. Acolhimento intercultural e ensino de português como língua adicional nas escolas municipais de Foz do Iguaçu. Revista Domínios de Linguagem. v. 12; n. 1, mar. 2018, p. 940-973, 2018.

ROCHA, C. H.; MACIEL, R. F. Ensino de língua estrangeira como prática translíngue: articulações com teorizações bakhtinianas. DELTA: Documentação de Estudos em Linguística Teórica e Aplicada, v. 31, p. 411-445, 2015.

SIQUEIRA, S. Inglês como Língua Franca: o desafio de ensinar um idioma desterritorializado. In: GIMENEZ, T.; CALVO, L.C.S. \& EL KADRI, M.S. Inglês como Língua Franca: ensino-aprendizagem e formação de professores. Campinas: Pontes, 2011.

UNILA. Acordo de cooperação técnica que entre si celebram a Universidade Federal da Integração Latino-Americana (UNILA) e o Município de Foz do Iguaçu, por meio da Secretaria Municipal de Educação (SMED). Foz do Iguaçu, 2018.

UNILA. Resolução CONSUN $n^{\circ} 05$ de 08 de abril de 2019. Política de Internacionalização da Universidade Federal da Integração Latino-Americana - UNILA, 2019.

UNILA/ UNIOESTE/ IFPR. Projeto de implementação de línguas adicionais nas escolas municipais: espanhol e inglês nas escolas. Grupo de Pesquisa: Linguagem, Política e Cidadania. UNILA/UNIOESTE/IFPR. Foz do Iguaçu, 2018.

WALSH, C. Interculturalidade crítica y pedagogía de-colonial: apuestas (des)de el insurgir, re-existir e re-vivir. Coleção Digital. PUC-Rio. 2012. Disponível em: <https:// www.maxwell.vrac.puc-rio.br/13582/13582.PDF>. Acesso em: 11 out 2018.

Recebido em: 10 fev. 2021. Aceito em: 04 mai. 2021. 